\title{
4. Vitellogenesis of the Isaza, Chaenogobius isaza, Controlled by the Subjective Diel Thermoperiod Caused by Vertical Migration
}

\author{
By Sachiko TAKAHASHI \\ Institute of Paleolimnology and Paleoenvironment on Lake Biwa, \\ Kyoto University, Takashima, Shiga 520-11 \\ (Communicated by Kiyoshi Takewakı, M. J. A., Jan. 12, 1982)
}

The Isaza, Chaenogobius isaza, is one of the teleost fish species endemic to Lake Biwa. The spawning season extends from April to June with the peak in early May. In most of the mature fish, the vitellogenesis starts synchronously in late November of the previous year (Takahashi, 1981a). From the fact that the oocyte development and the spawning are precisely timed in this species, it is supposed that the reproductive cycle is controlled by some seasonal fluctuation of environmental conditions.

It has been said that the Isaza show remarkable diel vertical migration. That the Isaza migrate between the lake bottom and the uppermost layer in winter was shown by Kobayashi and Yamanaka (1950). The midwater-trawling survey (Takahashi, 1981b) revealed that most of the population of the Isaza swim up from the lake bottom of about $50 \mathrm{~m}$ deep to the restricted thin stratum ranging from the upper layer of thermocline to the lower layer of epilimnion, between sunset and midnight in warm seasons. The temperature of the lake bottom where the Isaza stay in the daytime is almost constant (about $8^{\circ} \mathrm{C}$ ) throughout the year, while the temperature of the upper stratum where the Isaza swim up at night changes annually between about $8^{\circ} \mathrm{C}$ (in winter) and higher than $23^{\circ} \mathrm{C}$ (in summer). This means that the Isaza are exposed to conspicuously fluctuating temperature daily and annually in their diel vertical migration.

The preliminary experiments (Takahashi, 1981c) showed that in the Isaza reared under a relatively constant high water temperature $\left(17.5-20.2^{\circ} \mathrm{C}\right)$ the vitellogenesis did not start, while the vitellogenesis started in the Isaza subjected to the diel thermoperiod simulating that which is experienced by the fish in nature. It is clear that the constant high temperature inhibited the onset of the vitellogenesis. It remained to be studied, however, whether the gonadal response to the diel thermoperiod depended only upon the average temperature or on the thermoperiod itself.

Experiments were carried out to make clearer the relationship 
between the vitellogenesis and the diel thermoperiod (Takahashi, 1982). The temperature regimes of the experiments (see explanation of Fig. 1) were determined with the assumption that the seasonal temperature change of high-temperature phase in the thermoperiod would have important meaning in the control of the vitellogenesis of the Isaza. All the aquaria were shaded from the direct sunlight but

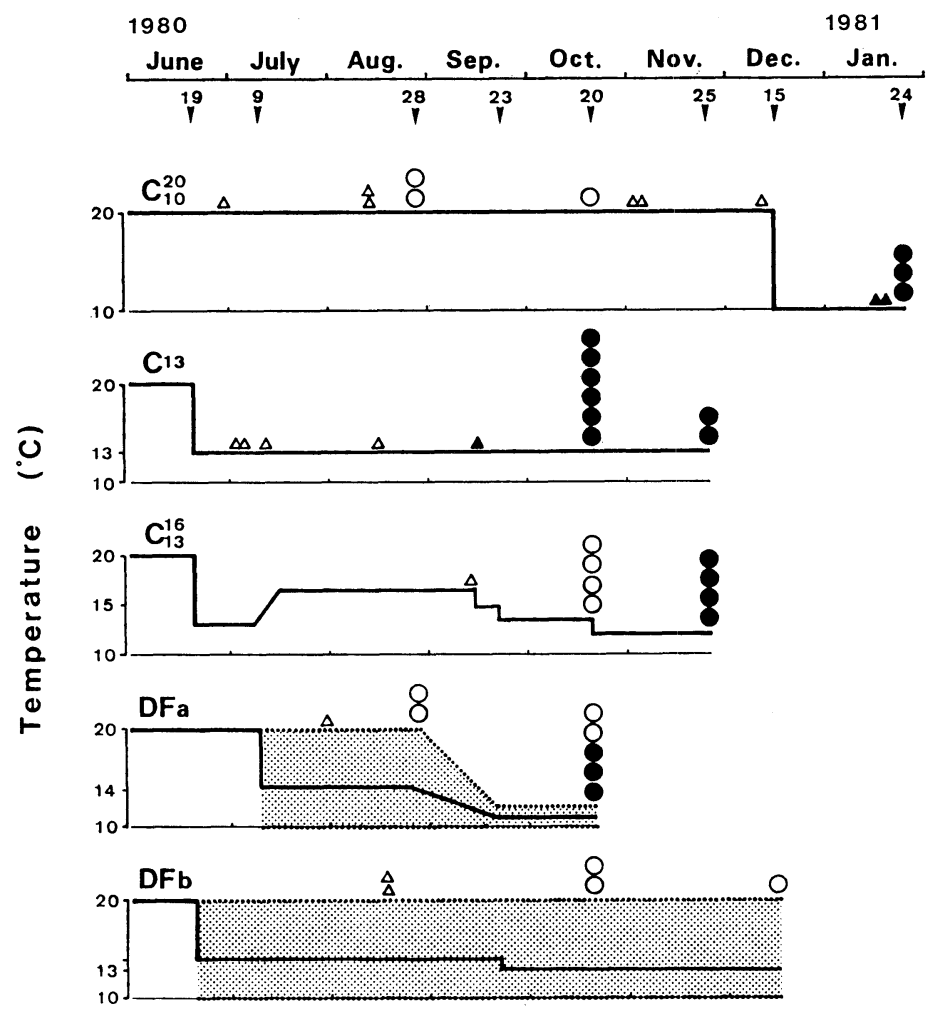

Fig. 1. Scheme of the temperature regimes of experiments and observation of the oocytes of each specimen. Solid lines indicate average temperature. Shaded zones indicate thermoperiod fluctuating daily. $\mathrm{C}_{10}^{20}$ : The relatively constant high temperature of around $20^{\circ} \mathrm{C}$, which was lowered to constant $10^{\circ} \mathrm{C}$ on and after December 15, 1980. $\mathrm{C}_{13}$ : The constant temperature of $13^{\circ} \mathrm{C}$, which represents the mean temperature of diel thermoperiod in DF regimes. $\mathrm{C}_{13}^{16}$ : Around $16-17^{\circ} \mathrm{C}$ in summer and around $13^{\circ} \mathrm{C}$ in autumn and spring. DFa: The diel thermoperiod fluctuating between $20^{\circ} \mathrm{C}(5-7 \mathrm{hrs}$ a day) and $10^{\circ} \mathrm{C}$. The temperature in the high-temperature phase started to decline on August 25, about 5 weeks ahead of natural temperature condition experienced by the Isaza in Lake Biwa. DFb: The diel thermoperiod fluctuating between $20^{\circ} \mathrm{C}$ and $10^{\circ} \mathrm{C}$ as DFa. However, the high temperature phase was maintained at around $20^{\circ} \mathrm{C}$ until the end of the experiment (December 15, 1980). In all groups fish were kept at $20^{\circ} \mathrm{C}$ until June 19 for acclimation. $\bigcirc$, a fish without yolk-laden oocytes; $\bullet$, a fish with yolkladen oocytes; $\Delta$ and $\Delta$, fish which died or weakened halfway with and without yolk-laden oocytes, respectively. 
photoperiod was not controlled. To observe the development of the oocytes, the fish were killed at appropriate dates and the ovaries were studied histologically.

The results of the experiments (Fig. 1) show that the average temperature lower than a certain threshold is one of the necessary factors for the onset of the vitellogenesis. The results of $\mathrm{C}_{10}^{20}$ regime seem to suggest that it takes about one month for the vitellogenesis to start after the lowering of water temperature below the threshold value. The actual threshold temperature appears to be higher than $13^{\circ} \mathrm{C}$, since the vitellogenesis started in the fish kept under constant $13^{\circ} \mathrm{C}\left(\mathrm{C}_{13}\right.$ regime $)$. On the other hand, the threshold temperature seems to be lower than $16^{\circ} \mathrm{C}$, since in the fish placed under the $\mathrm{C}_{13}^{16}$ regime, the vitellogenesis failed to start on October 20, after about one month during which the water temperature sometimes attained near $16^{\circ} \mathrm{C}$. It may be reasonable to estimate the threshold of average temperature $(T a)$ to be $14-15^{\circ} \mathrm{C}$.

In the fluctuating temperature regimes, the vitellogenesis did not start throughout in $\mathrm{DFb}$ and before lowering temperature of the high-temperature phase in $\mathrm{DFa}$ despite that average temperature was kept below $14-15^{\circ} \mathrm{C}$, i.e., below the Ta. This means that the hightemperature phase had an inhibitory effect. There must be another threshold of the high-temperature phase $(T h)$ for the vitellogenesis to be triggered. From the findings that the high-temperature phase of $15-16^{\circ} \mathrm{C}$ did not inhibit vitellogenesis in the previous experiment (Takahashi, 1981c) and that the vitellogenesis did not occur in the fish under the $\mathrm{DFb}$ regime although the temperature of the hightemperature phase dropped to around $18^{\circ} \mathrm{C}$ in October, the Th seems to lie around $16-18^{\circ} \mathrm{C}$.

The average water temperature experienced by the Isaza under the diel vertical migration remains below the $T a$ all the year round (Takahashi, 1981c). The vitellogenesis in the Isaza in nature beginning in late November appears to have been triggered about one month before, i.e., in late October, when the estimated water temperature of the upper stratum to which the Isaza swim up every night drops from about $18^{\circ} \mathrm{C}$ to $16^{\circ} \mathrm{C}$ level, i.e., below the $T h$ (Takahashi, 1981c). This is in good agreement with the result of the experiments.

Although high temperature around $20^{\circ} \mathrm{C}$ exerts an inhibitory effect on vitellogenesis, a transient exposure of the fish with young oocytes to this temperature seems to be indispensable for the normal development of oocytes. The oocytes of the fish which had been kept under constant $13^{\circ} \mathrm{C}\left(\mathrm{C}_{13}\right.$ regime $)$ underwent degeneration. To swim up to the upper stratum of Lake Biwa every night and to experience the high temperature is thus indispensable for the Isaza not only for 
the synchronized maturation but also for the normal development of the oocytes. To descend to lake bottom and experience the low temperature every day is also necessary for lowering the average temperature they experience below $T a$.

All these results indicate that the "subjective" thermoperiod, i.e., the daily temperature fluctuation experienced by the fish as the result of their diel vertical migration, is of primary importance in triggering and assuring the timely, synchronized and normal vitellogenesis of the Isaza.

The author thanks Prof. T. Hidaka of Kyoto Univ. for his valuable advice.

\section{References}

Kobayashi, S., and Y. Yamanaka (1950) : Rep. Shiga Pref. Fish. Exp. Stn., 1, 2-9.

Takahashi, S. (1981a): Zool. Mag., 90, 54-61.

- (1981b) : ibid., 90, 145-151.

(1981c) : ibid., 90, 265-270.

- (1982): ibid. (in press). 